\title{
Una primera aproximación a la Ley de regulación de las consultas populares locales en Andalucía 2/2001, de 3 de mayo
}

\author{
José Luis Rodríguez Rodríguez \\ Vicesecretario General de la Diputación de Sevilla \\ Profesor Asociado de la Universidad Pablo de Olavide
}

Sumario: I. INTRODUCCIÓN. II. EL RÉGIMEN JURÍDICO DE LAS CONSULTAS POPULARES. III. CONSIDERACIONES SOBRE ASPECTOS GENERALES DE LA LEY 2/2001, REGULADORA DE LAS CONSULTAS POPULARES LOCALES EN ANDALUCÍA. 1. El objeto de la convocatoria. 2. El sufragio universal, el cuerpo electoral, la acreditación del derecho de sufragio y la circunscripción electoral. 3. La Administración Electoral. Las Juntas Electorales. 4. Legislación supletoria. IV. DESARROLLO DEL PROCESO ANTES DE LA CONVOCATORIA DE CONSULTA POPULAR. 1. La iniciativa de la consulta. 2. Verificación de los requisitos en iniciativas de consulta de los vecinos. 3. La información pública. 4. Acuerdo de celebración. 5. Tramitación de la preceptiva autorización de la consulta. V. CONVOCATORIA DE LA CONSULTA POPULAR Y DESARROLLO POSTERIOR DEL PROCESO HASTA LA VOTACIÓN. 1. La convocatoria. VI. VOTACIÓN, ESCRUTINIO GENERAL Y PROCLAMACIÓN DE RESULTADOS. 1. Constitución de las Mesas. 2. Votación y escrutinio. 3. El escrutinio general y proclamación de resultados. VII. CONCLUSIONES.

\section{INTRODUCCIÓN}

En el Boletín Oficial de la Junta de Andalucía número 59, del día 24 de mayo de 2001, aparece publicado el texto de la Ley 2/2001, de 3 de mayo, de regulación de las consultas populares locales en Andalucía. Respecto del proyecto de Ley publicado en el Boletín Oficial del Parlamento de Andalucía (BOPA en lo sucesivo) de 18 de julio de 2000, número 28 , se han operado una serie de modificaciones que han mejorado el texto legal. A la fecha en que se redactan estas líneas, no se tiene constancia de la realización de corrección de errores sobre el texto promulgado, siendo éste el objeto de nuestro comentario ${ }^{1}$.

\footnotetext{
${ }^{1}$ En breve referencia a los prolegómenos de la LRCPLA, habría que decir que el ejecutivo andaluz ha tenido especial interés en la aprobación de la misma. Así, en la pasada Legislatura del Parlamento de Andalucía - la V- se comenzó la tramitación del Proyecto de Ley (n. ${ }^{\circ} 5-99 /$ pl-0008608), cuyo texto fue publicado en el BOPA, n. ${ }^{\circ} 368$, de 24 de septiembre de 1999. El proyecto decayó como consecuencia de la disolución del Parlamento y convocatoria de elecciones autonómicas, que se celebraron en el primer trimestre de 2000, dando lugar a la actual VI Legislatura, en la que nuevamente se ha retomado el proyecto siendo publicado en el BOPA, n. ${ }^{\circ} 28$, de 18 de julio de 2000, bajo el número 6-00/PL-000001. En esta nueva iniciativa legislativa las únicas modificaciones que se han operado, respecto al texto publicado en la legislatura anterior, consisten en el cambio de de-
} 
Durante la tramitación del proyecto de Ley de regulación de las consultas populares locales en Andalucía, y estando en la Comisión de Coordinación y Régimen de las Administraciones Públicas del Parlamento Andaluz, se invitó al Colegio de Secretarios, Interventores y Tesoreros de Sevilla para hacer las consideraciones que estimara oportunas con relación al mencionado proyecto. Esta iniciativa permitió a los distintos grupos parlamentarios conocer las sugerencias que desde este Colegio profesional se plantearon, tarea que me fuera encomendada. El fruto de la receptividad que tuvo ese trabajo se refleja en el texto aprobado definitivamente. El legislador andaluz ha introducido variaciones - algunas de ellas sustanciales - que han afectado de manera positiva al resultado final. Ello nos permite ahora analizar el texto legal desde la perspectiva que nos da el conocimiento de su proyecto para, desde su comparación, extraer las consideraciones que nos parecen oportunas realizar.

Una de las modificaciones operadas ha consistido principalmente en el acortamiento de los plazos de los distintos trámites a seguir en el proceso. También se aprecian algunas otras modificaciones - a las que aludiremos seguidamente-, que al comparar el proyecto de Ley presentado al Parlamento y el texto legal promulgado, deben ser calificadas todas, como convenientes y acertadas. Ello se observa desde la propia Exposición de Motivos y a lo largo de todo el articulado.

Respecto de los plazos se han concretado algunos que en el proyecto no figuraban, evitándose situaciones de pasividad que incidirían en una prolongación innecesaria del proceso. Entre ellos, podemos citar el contemplado en el artículo 8; artículo 24.4 y artículo 11.1 . También y en relación con los plazos, se han reducido algunos de ellos respecto del fijado en el proyecto. Es el caso del artículo 10.3 (de treinta pasa a veinte días); artículo 11.2 (la publicación del decreto de convocatoria ha de efectuarse entre los treinta y cuarenta días anteriores a la votación, en lugar de entre los treinta y sesenta días, del proyecto); artículo 13.1 y 2 (de quince pasa a diez días, en el primer apartado; y de diez a ocho días, en el segundo); artículo 24.1 y 4 (la emisión del voto anticipado se deberá hacer entre el vigésimo día siguiente al de publicación en el BOJA del decreto de convocatoria hasta el segundo día previo al de la votación).

nominación de la Consejería de Gobernación, a la que no se le añade «y Justicia», resultado de la reestructuración llevada a cabo por la Presidencia del Gobierno Andaluz tras las elecciones. Tanto la Exposición de Motivos como sus 27 artículos; tres disposiciones adicionales y tres finales, son del mismo tenor que el texto primitivo. La Ley $2 / 2001$ que comentamos tiene la misma estructura que el proyecto aludido, en el que durante el trámite parlamentario — como es lógico — se han operado las modificaciones a que aludiremos a continuación. 
El legislador andaluz consciente de que la duración del proceso es un factor muy importante ha aquilatado aquellos plazos que parecían muy amplios y ha concretado otros inexistentes. Ello va a permitir un desarrollo mucho más coherente de las consultas populares, aunque hubiera sido deseable contar como días naturales algunos de los plazos que la Ley fija en su cómputo como días hábiles, convirtiendo lo que debiera ser una excepción en casi una regla. Son muchos los plazos que se cuentan por días hábiles, como por ejemplo: en el artículo 7.1 y 2 ; artículo 8 ; artículo 10.3; artículo 11.1; artículo 13.1 y 2.

Sin embargo, la Ley de regulación de las consultas populares locales de Andalucía (en adelante, LRCPLA) ha dejado, tal como estaba recogida en el proyecto, una materia que deberá ser tenida muy presente por los Ayuntamientos a la hora de acordar la realización de una consulta a sus vecinos. Se trata de la cuestión económica que con la regulación actual, será el municipio ${ }^{2}$ - término empleado por la Ley - el que se haga cargo íntegramente de los gastos necesarios para el desarrollo del proceso (art. 14.2 LRCPLA). Como veremos más adelante, estos gastos pueden ser cuantiosos y su importe va a ejercer, sin ninguna duda, una gran cortapisa para poner en práctica esta forma de democracia directa que constituye la consulta popular.

Según nuestro punto de vista, que el municipio, a través de su Ayuntamiento, tenga que afrontar los gastos del proceso de consulta popular local frenará muchas iniciativas y convertirá esta manifestación de la participación directa del ciudadano en los asuntos públicos, en excepcional. Respecto de esto último, no hay que olvidar que el Tribunal Constitucional cuando se refiere a ellas tiene declarado, en su Sentencia 76/1994, de 14 de marzo, que

«(...) habrian de ser, en todo caso, excepcionales en un régimen de democracia representativa como el instaurado por nuestra Constitución, en el que "priman los mecanismos de democracia representativa sobre los de participación directa... ”» (Fundamento Jurídico 3. ${ }^{\circ}$ ).

Dicha excepcionalidad se reitera en la Sentencia de este mismo Tribunal 119/1995, de 17 de julio (BOE del día 22 de agosto), pero ello no puede significar que, por vía del coste económico, se llegue a la excepción puesto que ésta deberá venir fundada en la razonabilidad de las cosas, es decir, en función de las materias objeto de consulta y de la prudencia con

\footnotetext{
${ }^{2}$ Los artículos 10.4 y 14.2 se refieren al municipio, cuando en realidad debieran hacerlo al Ayuntamiento, ya que el artículo 3 del Estatuto de Autonomía de Andalucía (LO 6/1981, de 30 de diciembre) otorga a éste la «representación, gobierno y administración» del municipio.
} 
la que se acuda a estas consultas que no vinculan de derecho, pero sí lo harán de facto.

La Comunidad Autónoma andaluza, como tantas otras, tiene competencias para la regulación de las consultas populares ${ }^{3}$, según lo dispuesto en el artículo 15.2 de su Estatuto de Autonomía ${ }^{4}$.

Con esta LRCPLA se ha optado también por hacer uso de su competencia para normar una cuestión singular, «olvidando» que tiene aún pendiente la regulación y la configuración del régimen local andaluz. La LRCPLA se basa en la Ley Orgánica 2/1980, reguladora de las distintas modalidades de referéndums - cuya regulación no es aplicable a las consultas locales, como luego tendremos ocasión de exponer, por virtud de su Disposición Adicional- y en la regulación que Cataluña ha realizado — con algunas variaciones y añadidos - de las consultas populares en desarrollo del artículo 144 de la Ley 8/1987, de 15 de abril, municipal y de régimen local, a través del Decreto 294/1996, de 23 de julio (DOGC n. ${ }^{\circ} 2237$, del 31).

Junto con las consideraciones anteriores, ha de manifestarse también, como primera objeción, que la LRCPLA no regula un procedimiento de consulta popular especialmente ágil. Si tenemos en cuenta todos y cada uno de los trámites previstos y plazos que deben cumplirse en este proceso, emplearemos - entre el período en el que se decide ponerlo en marcha, su autorización, y su realización - no menos de nueve meses o un año - plazo que en nuestra opinión no debiera de ser superior a seis meses-, lo que dilata excesivamente su desarrollo ${ }^{5}$. Se convierte por ello en un proceso que, por su considerable prolongación, puede no ser asumido por las Corporaciones Locales, o por los vecinos que tienen la posibilidad de su iniciativa; o bien que, por la realidad de las materias objeto de consulta, impida dedicarse tanto tiempo a la preparación de una consulta sobre la que no se tiene la certeza de poderse llevar a cabo, puesto que, en

\footnotetext{
${ }^{3}$ Las CC.AA. que han incluido en sus Estatutos esta competencia son: Aragón, Asturias, Baleares, Cataluña, Castilla y León, Extremadura, Galicia, La Rioja, Murcia, y Navarra.

${ }^{4}$ Dice este artículo: «Corresponde a la Comunidad Autónoma el desarrollo legislativo del sistema de consultas populares locales en el ámbito de Andalucia, de conformidad con lo que dispongan las leyes a que se refiere el apartado 3 del artículo 92 y el número 1 y 32 del artículo 149.1 de la Constitución, correspondiendo al Estado la autorización de su convocatoria.»

${ }^{5}$ Si se formalizara una petición de consulta popular el 7 de enero del 2002, no será posible solicitar la autorización al Gobierno de la Nación antes de mediados del mes de mayo de ese año, y en el supuesto de que todos los trámites se realizaran sin dilación alguna. Por tanto, se podría contar con la autorización para la última quincena del mes de agosto, que obligaría a una convocatoria de la consulta durante el mes de septiembre para celebrarla a finales de octubre o en el mes de noviembre, en el mejor de los casos.
} 
último término, su autorización corresponde al Gobierno de la Nación (art. 71 Ley 7/1985, reguladora de las Bases de Régimen Local, en este trabajo LRBRL).

A ello ha de sumarse el papel confiado a la Consejería de Gobernación, a la que sólo se le encomienda la cooperación y asistencia activa (¿?) en el proceso, cuando así lo pida el Ayuntamiento interesado (Disposición Final segunda). Esta colaboración no será en ningún caso obligatoria para la Corporación pero constituirá, a buen seguro, una ayuda necesaria, máxime si se hace que ésta sea lo más amplia posible, abarcando también la asistencia en materia económica puesto que el coste del proceso, como ya indicábamos antes, se imputa totalmente al Municipio, según el artículo 14.2 de LRCPLA.

Para la mejor ilustración de este comentario, hemos confeccionado el esquema del proceso de consulta popular local en Andalucía, comenzando por su iniciativa y concluyendo con la publicación de los resultados (ver Anexo).

\section{EL RÉGIMEN JURÍDICO DE LAS CONSULTAS POPULARES}

La Exposición de Motivos de la LRCPLA comienza diciendo que

"Un Estado social y democrático debe garantizar a sus ciudadanos el ejercicio de los derechos constitucionales, siendo uno de ellos la participación en los asuntos públicos, directamente o por medio de representantes libremente elegidos en elecciones periódicas por sufragio universal, como recoge el artículos 23.1 de la Constitución Española.»

Si se compara este texto con el del proyecto podemos observar que en este primer párrafo se ha llevado a cabo un cambio sustancial, que mejora su contenido y significado.

La expresión «participar en los asuntos públicos» se recoge en el artículo 23.1 de la Constitución Española, y puede ejercerse por el ciudadano a través de sus representantes o bien, directamente como dice el precepto constitucional, lo que ha hecho decir al Tribunal Constitucional, cuando ha tenido ocasión de pronunciarse sobre ello (STC 119/1995, de 17 de julio, $B O E$ de 22 de agosto), que

«la participación directa que en los asuntos públicos ha de corresponder a los ciudadanos es la que se alcanza a través de las consultas populares previstas en la propia Constitución (arts. 92, 149.1.32, 151.1, 152.2, 167.3 y 168.3)», 
citando el fundamento jurídico $5 .^{\circ}$ de la anterior STC 63/1987, de 20 de mayo, y el fundamento jurídico $2 .^{\circ}$ del ATC 399/90. Y añade dicho Tribunal, Sentencia 119/95, que todas estas modalidades de referéndum corresponden a lo que

«tradicionalmente se vienen considerando como formas de democracia directa, es decir, aquellos supuestos en los que la toma de decisiones políticas se realiza mediante un llamamiento directo al titular de la soberanía».

En la Exposición de Motivos de la LRCPLA se hace referencia al derecho de los ciudadanos a la participación en los asuntos públicos, recogiendo un mandato establecido en el artículo 12.1 del Estatuto de Autonomía. Constituye un derecho fundamental, manifestación del artículo 23 de la CE, como forma de participación política y como expresión de la soberanía popular que excepcionalmente es ejercida directamente por el pueblo y que lo ostentan sólo — según el dictado constitucional del art. 23- «los ciudadanos». De conformidad con lo cual no son titulares de la situación jurídica así garantizada otras personas o entes (como, por ejemplo, los partidos políticos), y como dice la STC 63/1987

"procedimientos éstos en los que habrán de hacerse presentes, sin duda, los partidos y en general, las agrupaciones políticas, mas no como titulares del derecho mismo a la participación, sino en lo que a los partidos políticos se refiere, como instrumentos fundamentales que son para hacerle posible, concurriendo, como la Constitución quiere, a la formación y manifestación de la voluntad popular» (FJ 5. ${ }^{\circ}$.

(en este sentido la STS de 2-10-95 Arz. 6989). Por tanto, para determinar si estamos o no ante un derecho fundamental de participación política, encuadrable en el artículo 23.1 CE, habrá que atender no sólo a la naturaleza y forma del llamamiento sino también a su finalidad, ya que, como dice el TC, Sentencia 119/1995, sólo allí donde la llamada a la participación comporte el ejercicio directo o por medio de representantes, del poder político - esto es, sólo allí donde se llame al pueblo como titular de ese poder - estaremos en el marco del artículo 23.1 y podrá aducirse el derecho fundamental aludido.

Como expresión de esta participación ciudadana, la $\mathrm{CE}$ en su artículo 92.1 dispuso que «las decisiones politicas de especial trascendencia podrán ser sometidas a referéndum consultivo de todos los ciudadanos» señalando, el número 3 del propio precepto, que «una ley orgánica regulará las condiciones y el procedimiento de las distintas modalidades de referéndum previstas en la Constitución», sin que en dicho artículo se mencionen las consultas populares que deben encuadrarse dentro de las distintas modalidades de referéndum a regular mediante Ley, como así lo 
ratifica el propio texto constitucional, en el artículo 149.1.32.a al disponer que el Estado tiene competencia exclusiva en la «autorización para la convocatoria de las consultas populares por vía de referéndum».

El desarrollo de este mandato constitucional se produjo mediante la Ley Orgánica 2/1980, de 18 de enero, reguladora de las distintas modalidades de referéndum (LO 2/1980, en lo sucesivo), posteriormente modificada por la LO 12/1980, de 16 de diciembre - que modifica a su vez la redacción del artículo 8.4 como resultado del celebrado para la autonomía andaluza-. Esta Ley Orgánica, que regula tanto el procedimiento como las condiciones de estos referéndums, en su artículo 2.1, recoge el mandato contenido del artículo 149.1.32. ${ }^{\mathrm{a}}$ de la CE y dice que

«la autorización para la convocatoria de consultas populares, por vía de referéndum en cualquiera de sus modalidades, es competencia exclusiva del Estado»

pero matizando, mediante su Disposición Adicional, que las disposiciones de dicha Ley

«no alcanzan en su regulación a las consultas populares que puedan celebrarse por los Ayuntamientos relativas a los asuntos relevantes de indole municipal, en sus respectivos territorios, de acuerdo con a legislación de Régimen Local, y a salvo, en todo caso, la competencia exclusiva del Estado para su autorización».

Como ya se dijo al principio, la Comunidad Autónoma andaluza recoge en el artículo 15.2 de su Estatuto de Autonomía la competencia para el desarrollo legislativo de las consultas populares locales en su territorio,

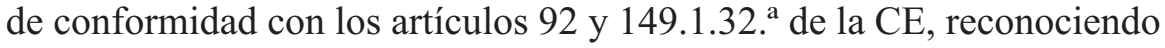
la competencia exclusiva del Estado para la autorización de la convocatoria. En ejercicio de esta competencia se aprueba por su Parlamento esta LRCPLA 2/2001, de 3 de mayo, que ahora analizamos.

La regulación de las consultas populares en la legislación local, cuando ello se aborda en la Exposición de Motivos de la LRCPLA, se menciona adecuadamente el artículo 71 de la Ley 7/1985, reguladora de las Base de Régimen Local (en adelante LRBRL), ubicado dentro del Capítulo IV (Título V) titulado «Información y participación ciudadanas» Dicho artículo afirma que de conformidad con la legislación del Estado y de la Comunidad Autónoma, cuando ésta tenga competencia estatutariamente atribuida para ello, los Alcaldes, previo acuerdo por mayoría absoluta del Pleno y autorización del Gobierno de la Nación, podrán someter a consulta popular (actividad no delegable según el art. 43.1 ROF) aquellos 
asuntos de la competencia propia municipal y de carácter local, que sean de especial relevancia para los intereses de los vecinos, con excepción de los relativos a la Hacienda Local ${ }^{6}$.

Pero además de este artículo de la Ley 7/1985, la Exposición de Motivos de LRCPLA se completa con la referencia también del artículo 18.1.f), que regula el «estatuto del vecino», cuando dice que son derechos y deberes de éste «f) pedir consulta popular en los términos previstos en la Ley», desarrollado en el artículo 226 del ROF, dentro del Título VII, Cap. I, ESTATUTO DEL VECINO, y el artículo 56.1 del Reglamento de Población y Demarcación territorial de las Entidades Locales, aprobado por R.D. 1690/1986, de 11 de julio (RP).

Analizaremos la LRCPLA examinando aspectos generales del texto para, más tarde, desarrollar el proceso distinguiendo las actuaciones previas a la convocatoria - principalmente la iniciativa-; la convocatoria y posteriores trámites, para terminar con una breve referencia a la votación y el escrutinio de los resultados.

\section{CONSIDERACIONES SOBRE ASPECTOS GENERALES DE LA LEY 2/2001, REGULADORA DE LAS CONSULTAS POPULARES LOCALES EN ANDALUCÍA}

\section{El objeto de la convocatoria}

El artículo primero de la LRCPLA establece el objeto de la norma en «la regulación de las consultas populares locales» para seguidamente, en el artículo segundo, fijar los asuntos objeto de la consulta popular local.

En el apartado 1 de este artículo primero se define la consulta popular como «instrumento de conocimiento de la opinión de los vecinos sobre asuntos de la competencia propia municipal...», que ha de ceñirse a los límites fijados por la LO 2/1980; Ley 7/1985 LRBRL, y el propio texto de la LRCPLA, que se resumen en:

\footnotetext{
${ }^{6}$ La jurisprudencia del Tribunal Supremo, en la Sentencia de 14-11-89 (Arz. 8304), analiza toda esta normativa y los requisitos que debe reunir una petición de consulta popular, diferenciandola del derecho de petición, con motivo de la construcción del Metro de Sevilla.
}

Resulta también interesante la STS de 22-1-93 (Arz. 457). 


\section{Objeto:}

— asuntos de la competencia propia municipal ${ }^{7}$ (art. 2.1)

— asuntos que sean de especial relevancia para sus intereses (art. 2.1)

— asuntos de carácter local (art. 2.1) ${ }^{8}$

$$
\text { Límites: (excluyentes) }
$$

— asuntos contrarios al ordenamiento jurídico (art. 2.2)

- asuntos que menoscaben las facultades de decisión que corresponden a los órganos de gobierno ${ }^{9}$ (art. 2.2)

\section{— materias propias de la Hacienda Local (art. 2.3)}

En este artículo se omite una expresión que figura en la Disposición Adicional de la LO 2/1980, alusiva a la territorialidad de la consulta cuando indica que las cuestiones objeto de las mismas serán asuntos relevantes de índole municipal en sus respectivos territorios. Aspecto que no deja de tener importancia porque pueden existir algunos asuntos que cumplan todos los requisitos propios del objeto de una consulta popular, pero que no tengan esta vinculación territorial a la que hace alusión la DA y que no se incluye en el texto de la LRCPLA. La STS 14-11-89 (Arz. 8304) ya se refiere a este tema cuando dice que

«la cuestión que se discute deberá poseer el carácter local, de modo que su planteamiento, no podrá superar los límites geográficos del término municipal...».

En el artículo 4 se fijan otro tipo de límites que no vienen determinados por el objeto de la consulta, sino que lo son en razón del momento

\footnotetext{
${ }^{7}$ Cfr. el artículo 25 LRBRL. Sobre este particular la STS de 22-1-93 (Arz. 457).

${ }^{8}$ La STS de 17-2-00 (Arz. 77), en su fundamento de derecho quinto, dice «(...) La consulta popular a los vecinos no se permite para cualquier asunto, ni siquiera para aquellos que tengan un interés relevante para los vecinos; es preciso, además, que se trate de asuntos de "carácter local", de un lado, y que respecto de ellos el municipio tenga "competencias propias", por otro.»

9 Aunque la LRCPLA menciona «órganos representativos», las competencias se atribuyen al Municipio (art. 25 LRBRL), cuyo gobierno y Administración municipal corresponde al Ayuntamiento, integrado por el Alcalde y Concejales (art. 19.1 LRBRL). El Ayuntamiento es quien ostenta la representación del Municipio [art. 1.1 R.D.Lvo. 781/86, que aprueba el texto refundido de disposiciones legales vigentes en materia de régimen local (TRRL)], y art. 3.1 del Reglamento de Organización, Funcionamiento y Régimen Jurídico de las Entidades Locales (ROF). El Ayuntamiento es el órgano de gobierno y administración del Municipio (art. 35.1 ROF), que se integra por el Alcalde, Tenientes de Alcalde y el Pleno. Son los Concejales los que son elegidos mediante sufragio universal, igual, libre, directo y secreto, y son la representación del pueblo soberano en el Ayuntamiento.
} 
temporal en que la misma se quiera llevar a cabo. Es decir, éstas no podrán ser convocadas ni tener lugar cuando sean coincidentes con elecciones generales, autonómicas, europeas o con un referéndum, cuyo ámbito territorial - que no se recoge en el art. 2- afecte al de la consulta popular.

Si los procesos electorales mencionados en el artículo 4.1 se convocasen con posterioridad a la convocatoria de una consulta popular local, ésta — nos dice el apartado 2 de dicho artículo- deberá quedar automáticamente sin efecto. Se produce así una desconvocatoria, por imperativo legal, que se compensa con el mandato que el artículo 4.2, in fine, efectúa al obligar a una nueva convocatoria de la consulta tras la celebración de los procesos electorales que originaron aquella desconvocatoria ${ }^{10}$.

El último de los límites fijados, en el artículo 4.3, no lo es por razón del momento en que se produce la convocatoria sino por el objeto, al igual que los contemplados en el artículo 2. Cuando un asunto ha dado origen a la celebración de una consulta no puede ser sometido a una nueva durante el período de tiempo que resta a la Corporación municipal para agotar su mandato, añadido este último que debe sobreentenderse ya que no figura en el texto legal. Para que opere esta limitación se deben dar dos condiciones: a) que el asunto haya dado origen a la celebración - efectivade una consulta; $\mathrm{y} b$ ) que fuere cual fuere el resultado de aquella consulta, la Corporación convocante no puede volver a hacer otra durante «el período de tiempo que le reste».

\section{El sufragio universal, el cuerpo electoral, la acreditación del derecho de sufragio y la circunscripción electoral}

Según el artículo 3 de la LRCPLA, la consulta popular se decidirá en iguales términos que cualquier otro proceso electoral, mediante sufragio universal - reconocido en el art. 23 de la CE - libre, igual, directo y secreto, como se recoge también en el artículo 2 y siguientes de la Ley Orgánica reguladora del Régimen Electoral General (LOREG), y artículo 5 de la LO 2/1980, para los referéndums.

Sin embargo, cuando el artículo 3 simplemente debiera hacer titular de este sufragio activo a los vecinos, menciona - creemos que equivocadamente- a los electores que componen el cuerpo electoral al que se refie-

10 El proyecto decía que «podía» celebrarse una nueva consulta tras la celebración de los procesos a los que se alude, por lo que la nueva convocatoria era facultativa. 
re el artículo 15 de esta Ley. Por su parte, el artículo 15.1 de la LRCPLA establece que este cuerpo electoral está integrado por «los vecinos del municipio que (...) gocen del sufragio activo en las elecciones municipales».

También en el artículo 6.3 de la LRCPLA, cuando dice quién puede suscribir una petición de iniciativa de consulta popular, alude a los «vecinos del municipio que gocen de sufragio activo...».

El sufragio activo sólo se le reconoce, en el artículo 13.2 de la Constitución Española, a los españoles «que sean titulares de los derechos reconocidos en el artículo $23 \mathrm{CE}$, salvo lo que, atendiendo a criterios de reciprocidad, puedan establecerse por tratados o ley... en las elecciones municipales». Por su parte, el artículo 2 de la LOREG otorga este derecho a los españoles mayores de edad, excepto los que carecen de él según el artículo 3 LOREG, añadiendo que para su ejercicio es indispensable la inscripción en el censo electoral vigente, como también tiene declarado la Junta Electoral Central (JEC) en el Acuerdo de 28-5-95.

Por lo tanto, si en una consulta popular este sufragio sólo es reconocible a los españoles vecinos del lugar, mayores de edad, inscritos en el correspondiente Padrón de habitantes, exigiéndose para su ejercicio la inscripción en el censo electoral, no cabe el ejercicio del derecho de sufragio por quien no esté inscrito en el censo electoral (Ac. 23-2-79) ${ }^{11}$.

El censo electoral tiene por finalidad posibilitar el control de las operaciones electorales para que no ejerzan el derecho de sufragio aquellos que no tienen legalmente el derecho al mismo (Ac. 5-5-77) ${ }^{12}$. Es por tanto el único medio para acreditar el derecho al sufragio al que debiera mencionarse en el artículo 16, en lugar de hacerlo a la «lista de electores». En la práctica, a pesar de esta inexactitud terminológica de la LRCPLA, será la lista del censo electoral vigente a la fecha de la convocatoria el único documento que expedirá la Delegación Provincial de la Oficina del Censo Electoral. «Cómo si no se explicaría que esta misma Oficina pueda certificar el derecho a estar incluido en "las listas del censo electoral", como medio de acreditación del derecho de sufragio (art. 16)» o ¿por qué el artículo 24.2 de la Ley, para ejercer el voto anticipado, exige aportar certificación «de inclusión en las listas del censo electoral»? La conclusión es

\footnotetext{
${ }^{11}$ Cfr. Código Electoral, 3. ${ }^{\text {a }}$ edición. El Consultor de los Ayuntamientos y los Juzgados, Publicaciones Abella, p. 34.

12 Ob. cit. Código Electoral, p. 34.
} 
bien fácil: unas listas y otras son la misma cosa. Aquella a que alude la LRCPLA es la lista del censo electoral.

Los vecinos que ostentan el derecho de sufragio activo en las elecciones municipales son los incluidos en el censo electoral y, de conformidad con el artículo 34.2 LOREG, "para cada elección se utilizará el censo electoral vigente el día de la convocatoria» y no las «listas electorales» como se dice — creemos que inapropiadamente — en los artículos 15 y 16 del texto legal comentado.

Como ya tiene declarado la STC 154/88

«... no existe un derecho a tal inscripción separado del sufragio y este comprende el de estar inscrito en el censo...».

De ahí la crítica que se hace al artículo 15.1 de la LRCPLA, para rechazar el uso de la expresión «cuerpo electoral». Este cuerpo electoral no puede ser otro que los vecinos del municipio incluidos en el censo electoral actualizado antes de la fecha de solicitud de consulta popular, puesto que la naturaleza del censo es declarativa y no constitutiva del derecho al voto o al sufragio activo ${ }^{13}$.

Respecto de la circunscripción electoral, decía el proyecto de la LRCPLA que "A los efectos de esta Ley, es el municipio». Tal dicción - desde nuestro punto de vista, errónea - podía estar inspirada en la regulación que el artículo 5.2 de la LO 2/1980 hace de la circunscripción para el referéndum, pero con base territorial en la provincia. Sin embargo, si atendemos a lo que dice el artículo 179 de la LOREG para las elecciones municipales, la circunscripción es el término municipal, esto es «el territorio en que el Ayuntamiento ejerce sus competencias» (art. 12. LRBRL y art. 1 Reglamento de Población), mientras que el Municipio se conceptúa, en el artículo 11 de la Ley 7/1985, como «la entidad local básica de la organización territorial del Estado» que «tiene personalidad jurídica y plena capacidad para el cumplimiento de sus fines», en el que el territorio es uno de sus elementos (art. 11.2 LRBRL); otro la población, es decir, los vecinos; y finalmente, la organización territorial.

\footnotetext{
13 En esta materia no se ha seguido por el legislador andaluz el artículo 10.1 del Decreto 294/1996, por el que se aprueba el Reglamento de Consultas Populares de Cataluña. En éste se expresa que el cuerpo electoral en las consultas populares ha de estar formado por los vecinos inscritos en el padrón de habitantes vigente a la fecha de la convocatoria en el municipio de que se trate y que reúnan los requisitos para ser electores según la legislación electoral vigente.
} 
Entonces, debe concluirse que, en este artículo 5 de la LRCPLA, el legislador autonómico ha realizado una certera modificación al sustituir «el municipio» por «el término municipal» para la determinación de la circunscripción electoral.

\section{La Administración Electoral. Las Juntas Electorales}

En el artículo 12 de la LRCPLA se regula la Administración Electoral a los efectos de la convocatoria, desarrollo y conclusión de las consultas populares locales andaluzas, fijando una estructura que parte, verticalmente considerada, de la Mesa electoral, la Junta Electoral de Zona (JEZ) y termina en la Junta Electoral de Andalucía (JEA). El artículo concluye refiriéndose a la finalidad de esta Administración electoral, es decir, "garantizar la objetividad y transparencia de la consulta», objetivo que resulta completado - si lo comparamos con el proyecto- con el principio de igualdad, como se recoge, por ejemplo, en el artículo 8.1 de la LOREG o la Instrucción de la JEC de 13-9-99 (BOE del día 16 n. ${ }^{\circ} 222$ ).

En el artículo 13 de la LRCPLA, dedicado a la JEZ, se han operado dos modificaciones siendo, a nuestro juicio, una de ellas de mucha relevancia. La primera se recoge en el apartado 1, cuando establece que para la composición de la JEZ con los vocales judiciales se sigue lo dispuesto en el artículo 11 de la LOREG; mientras que para los no judiciales, se fija el décimo día hábil siguiente a la publicación de la convocatoria de consulta popular en el BOJA, lo que ha reducido en cinco días hábiles el plazo que fijara el proyecto de Ley. Como consecuencia, el plazo que se recoge en el apartado dos de este artículo ha sido también reducido en dos días, de tal forma que cuando la propuesta no tenga lugar antes del octavo siguiente a la publicación de la convocatoria en el BOJA, la JEA procederá a su designación.

La segunda modificación, y creemos que la más importante de este artículo 13, la constituye su apartado 3, en el que se regula la recurribilidad de los acuerdos de la JEZ ante la JEA, el plazo establecido para ello, el procedimiento y la posterior inexistencia de recursos contra las decisiones de esta última Junta. Ello ha supuesto una novedosa aportación de la Ley, realizada dentro del trámite parlamentario, que ha paliado una de las omisiones más significativas de que adolecía el proyecto ${ }^{14}$.

${ }^{14}$ La segunda gran omisión que sigue existiendo en el texto legal es, a nuestro entender, el no contemplar la supletoriedad de la LOREG en todo lo no regulado por la LRCPLA. 
La JEZ tendrá las funciones que a la misma se le encomiendan en la LRCPLA (art. 11.1; art. 12; art. 13; art. 18; art. 20.4; art. 22.1; art. 24, y art. 25 y siguientes). Además, con carácter supletorio, debieran ser las fijadas para la misma en la LOREG (arts. 19.2, 20, 21, 26, 27, 56, 76, 78, $80,81,84,186,187,189,191,199,205$ y 206). Pero estas funciones no han sido especificadas de esta forma, e incluso la LRCPLA, cuando en su Disposición Final primera regula la legislación supletoria, menciona únicamente a la Ley Electoral de Andalucía.

Dentro de esta regulación de la Administración Electoral, se incluye un segundo apartado al artículo 14, por el cual «corresponde también al municipio hacerse cargo de los gastos necesarios para el desarrollo del proceso». Y nos preguntamos, ¿cuáles son estos gastos? ¿Lo son las asignaciones económicas de los miembros de la JEA, JEZ y Mesas? ¿Quién determina qué gastos son necesarios? ¿Quién pagará los gastos que no sean necesarios? ¿La campaña institucional, es un gasto necesario?

Estos gastos para el desarrollo del proceso, necesarios o no, van a suponer un importarte desembolso para las arcas municipales que la mayoría de las veces, consideramos, no se estará en condiciones de afrontar. Paradójicamente, en esta cuestión la LRCPLA no ha seguido la norma catalana, la cual fija que el Ayuntamiento se hará cargo de los gastos a partir de la publicación de la convocatoria de la consulta, mientras que en el texto andaluz le corresponden todos los gastos necesarios (¿?) que se puedan producir.

Como decimos, el hecho de que el municipio ${ }^{15}$ deba hacerse cargo de todos los gastos necesarios para el desarrollo del proceso de consulta popular implicará, entre otras muchas, la obligación de abonar las dietas de Juntas Electorales (Andaluza y Local), de miembros de Mesas electorales, Fuerzas y Cuerpos de Seguridad, representantes de la Administración, etc., cuyo elevado importe puede hacer inviable la convocatoria de la consulta por falta de recursos económicos. Con esta imputación de los gastos necesarios u obligación de hacerse cargo de los ocasionados en el desarrollo del proceso, consideramos que se trata de evitar el empleo inadecuado de la consulta popular, y que se convoque como algo excepcional. Pero, en cualquier caso, se considera necesario que se especifiquen los gastos que el municipio tiene que soportar como mínimo, posibilidad que se abre por aplicación de la Disposición Final segunda, que faculta a

${ }^{15}$ Se emplea de nuevo en este artículo 14.2 el término «municipio», cuando hubiera sido más correcto referirse al Ayuntamiento, que es donde recae la administración municipal y al que en cualquier caso se imputará cualquier gasto que se produzca. 
la Consejería de Gobernación de la Junta de Andalucía para dictar cuantas disposiciones sean precisas para el desarrollo y ejecución de lo previsto en la LRCPLA.

\section{Legislación supletoria}

En la Disposición Final primera de la LRCPLA se remite a la Ley Electoral de Andalucía 1/1986, de 2 de enero, para todo lo no previsto en la Ley de Consulta Popular 2/2001, debiéndose tener en cuenta su adaptación a las características y ámbito de la consulta. Es llamativo que no haga mención a la LOREG refiriéndose a ella como legislación supletoria, cuando a lo largo del articulado de la Ley se remite a la legislación electoral general para la regulación de algunas actuaciones (art. 18.3) o bien para decir que lo establecido en la misma es de aplicación directamente en esta Consulta Popular (arts. 13 y 18.1). Esta falta de remisión expresa a la LOREG debería haberse subsanado en el texto de la Ley, puesto que la mayoría de las lagunas que se presenten no podrán ser colmadas de otra forma que acudiendo a la Ley electoral estatal. Y debe ser así ya que, estimamos, no es conveniente apartarse de la LOREG en todo aquello que es común para todos los procesos electorales.

\section{DESARROLLO DEL PROCESO ANTES DE LA CONVOCATORIA DE CONSULTA POPULAR}

Antes de la convocatoria de una consulta popular, como parte del desarrollo previo del proceso que nos llevaría a ella y su posterior celebración, se deben llevar a cabo unas actuaciones que serán las que determinen si la iniciativa reúne los requisitos exigidos por la LRCPLA y comprobados éstos, el sometimiento posterior de la misma para su consideración municipal, aprobando la iniciativa de la convocatoria.

La LRCPLA, cuando regula el procedimiento para la convocatoria de las consultas populares, lo hace principalmente estableciendo un pormenorizado cúmulo de requisitos exigibles en los casos de iniciativas vecinales, mientras que para los casos en que ésta sea de la Corporación municipal —esto es, una iniciativa «oficial»—, sólo establece que el acuerdo de iniciación del procedimiento (art. 6.1) sea adoptado por mayoría simple, pero no exige ningún otro requisito más (art. 6). Es decir, la LRCPLA para las iniciativas oficiales no es muy exigente; sin embargo, para las que puedan surgir a solicitud de un grupo de vecinos, trata de garantizar la adecuada acreditación de su identidad, fija el número mínimo 
de firmas de vecinos necesarias para ello, exige la identificación del/los representante/s de los mismos, y finalmente todos estos requisitos desembocan en el acuerdo por el que se decide sobre la aprobación de la iniciación del procedimiento, que la Ley llama de aceptación de la solicitud de consulta (art. 8). En cualquier caso, lo que parece obligado es que este acuerdo ha de adoptarse, si se cumplen los requisitos exigidos en el artículo 6 , sobre lo que seguidamente tendremos ocasión de profundizar.

\section{La iniciativa de la consulta}

En el artículo 6 de la LRCPLA se regula la iniciativa en el procedimiento para la convocatoria de una consulta popular, que puede ser ejercitada por

a) La Corporación local, por un lado.

Cuando la iniciativa es de la propia Corporación tan sólo requiere:

- la propuesta de un grupo municipal y

— un acuerdo plenario adoptado por mayoría simple.

La iniciativa que hemos denominado «oficial» debe provenir de un grupo municipal, exigencia ésta que se incluye en la Ley y que no estaba en el proyecto. Es un matiz que puede resultar intrascendente, pero entendemos que no debe ser así. Cuando los grupos municipales (art. 73.3 de la LRBRL y arts. 23 a 29 del ROF) estén regulados adecuadamente mediante los Reglamentos Orgánicos propios de cada Corporación, habrá que estar a lo que en los mismos se disponga sobre ellos ${ }^{16}$. En caso de no contar con esta regulación, nos podríamos preguntar: ¿puede, por ejemplo, el único representante del grupo mixto tener esta iniciativa?, ¿tiene la consideración de grupo político, a estos efectos, un grupo mixto con un solo concejal? Las interpretaciones pueden ser muchas y variadas, y sin duda, lo que aparentemente resulta poco significativo, dará lugar a la necesidad de interpretar la norma en momentos de un presumible escaso sosiego político.

b) A solicitud de un grupo de vecinos, por otro.

Cuando la iniciativa es de los vecinos debe reunir los requisitos que seguidamente se indican, según los apartados 1 al 4, del artículo 6 .

16 Véase la STS de 15-9-95 (RA. 6701) sobre esta cuestión, y los comentarios que sobre el tema se hacen en la p. 1218 del Nuevo Régimen Local, tomo I, 4. ${ }^{\text {a }}$ edición de la Redacción de El Consultor de los Ayuntamientos, Madrid, 2001. 
Contrasta la inexistencia de un quórum determinado cuando la iniciativa es a solicitud de los vecinos, por lo que ante ello podrá interpretarse también que el acuerdo que adopte la Corporación municipal lo será igualmente por mayoría simple (art. 47.1 LRBRL).

El acuerdo del Pleno será de iniciación del proceso de consulta para la propiciada por la propia Corporación, o de aceptación de la solicitud de consulta cuando la petición es de un grupo de vecinos (art. 8).

Requisitos de la iniciativa vecinal:

— ha de efectuarse por escrito (art. 6. 1, 2 y 3);

— por vecinos censados (art. 6.3), es decir, que gocen del derecho de sufragio activo en las elecciones municipales;

- ha de constar en el escrito el DNI de cada uno de los vecinos (art. 6.2);

- ha de ser firmada: por un número determinado de vecinos, según la población y ante el Secretario municipal o fedatario público (art. 6.2);

- ha de designarse un representante por los vecinos firmantes (art. 6.4).

Una de las importantes variaciones apreciadas en el LRCPLA respecto de su proyecto la encontramos en este artículo y tiene relación con la iniciación del procedimiento a solicitud de los vecinos, en cuanto al número mínimo de firmas exigido para ello.

En los cuatro tramos poblacionales que se contemplan para la cuantificación del aval mínimo de firmas de los proponentes-vecinos - que no habitantes como dice la Ley ${ }^{17}$ - , se parte en el primer tramo de un por-

${ }^{17}$ Dice el artículo 15 de la LRBRL que «Toda persona que viva en España está obligada a inscribirse en el Padrón del municipio en el que resida habitualmente. Quien viva en varios municipios deberá inscribirse en el que habite durante más tiempo al año. Los inscritos en el Padrón municipal son los vecinos del municipio. La condición de vecino se adquiere en el mismo momento de su inscripción en el Padrón». Este artículo se desarrolla en los artículos 53 y 54 del Reglamento de Población, estableciéndose en el apartado 3 de este último que «el conjunto de los vecinos constituye la población del municipio». Correlativo con la anterior regulación, el artículo 18,f) de la LRBRL reconoce, entre los derechos y deberes de los vecinos, el de pedir la consulta popular en los términos previstos en la Ley, lo que se reitera en el artículo 56 del Reglamento mencionado, cuando establece que «la condición de vecino confiere los siguientes derechos y deberes...

A los efectos de esta Ley, debe considerarse que cuando se habla de habitantes se hace referencia a vecinos. 
centaje (\%) mínimo exigible para pedir iniciación del proceso de consulta, y a partir de municipios con más de cinco mil habitantes - tramos segundo a cuarto-, a un número fijo de firmas, se suma un porcentaje que variará según se trate de municipios comprendidos entre 5.001 a 50.000; de 50.001 a $100.000 ; y$ de más de 100.000 habitantes ${ }^{18}$. En el proyecto se recogían tan sólo tres tramos (hasta 5000; de 5001 a 100.000, y más de 100.000 hab.) que ofrecían unos resultados que eran desproporcionados, si se comparaban los obtenidos en los distintos municipios.

Estas firmas han de ser formalizadas ante el Secretario de la Corporación, tal como dispone el apartado 2 de este artículo, que con la modificación antes apuntada deja de ser copia literal de la reglamentación catalana. Creemos que se debería haber concretado aún más qué clase de fedatario público puede «formalizar» las firmas de los vecinos peticionarios de la consulta, ya que con el término empleado por la LRCPLA podrá interpretarse que este cometido puede realizarlo, además del Secretario municipal, los Notarios, los Secretario judiciales, corredores de comercio, etc.

Por otro lado, cuando en este apartado se exige que las firmas estén «formalizadas», surge la duda acerca de qué es lo que se quiere decir con esta formalización. Si interpretamos que las firmas han de formalizarse ante el Secretario o fedatario para «revestir de los requisitos legales», como define el término el diccionario de la lengua o si entendemos que lo que se pretende realmente es una autenticación de las firmas que apoyan la petición, al igual que se hace en el caso regulado por el artículo 187.2 y artículo 197.1.b) de la LOREG (para las agrupaciones de electores y moción de censura). Hubiera resultado más conveniente que en ambos términos - formalización y clase de fedatario — se hubiera seguido la dic-

\footnotetext{
18 Así, con la redacción dada al artículo 6 de la LRCPLA, se precisan las firmas mínimas que se indican seguidamente, según el número de vecinos de cada Municipio:

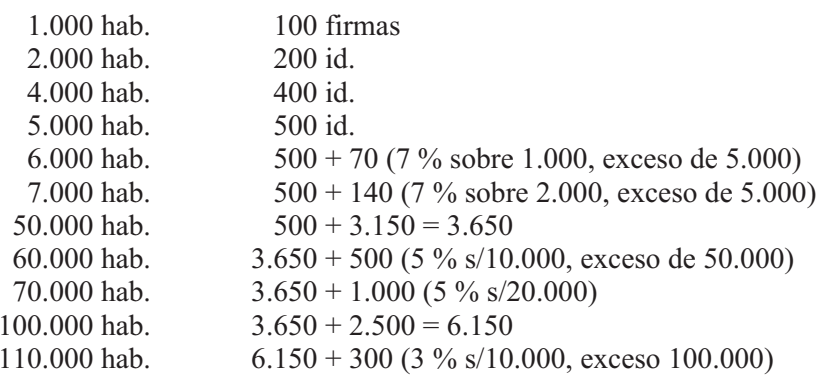

Se redondean los números para hacer los cálculos de manera más fácil. 
ción empleada por los preceptos de la Ley electoral, es decir, la autenticación de las firmas por el Secretario del Ayuntamiento o Notario.

\section{Verificación de los requisitos en iniciativas de consulta de los vecinos}

El Alcalde tiene aquí un importante protagonismo ya que, por un lado, verifica los requisitos que se exigen para que el grupo de vecinos pueda solicitar la consulta popular y, por otro, requiere la subsanación de los mismos cuando se observen defectos o falta de algunos de los exigidos.

En primer lugar, comprueba la adecuación de la iniciativa a los artículos 2, 4 y 6 de la LRCPLA, adoptando el Alcalde las medidas en orden a la verificación de lo siguiente:

- que el asunto sea de la competencia municipal, de carácter local, de relevancia para los intereses locales;

— que la iniciativa se formule en uno de los períodos excluidos de consulta;

- que la iniciativa se haga por escrito por quienes tienen la condición de vecinos; contiene las identificaciones de los firmantes que avalan la petición así como número de firmas mínimas exigibles con la formalización — autenticación - de todas ellas; so $\mathrm{y}$

— que los vecinos firmantes de la iniciativa estén incluidos en el cen-

— que en el escrito conste la designación de un representante de los vecinos.

La novedad de la Ley con respecto del proyecto en este artículo 7, se contempla en el apartado 1 in fine, al decir que «corresponden al Alcalde la adopción de las medidas procedentes en orden a la comprobación de los requisitos de la iniciativa, cuya certificación corresponderá al Secretario de la Corporación». Ante ello nos preguntamos qué debe contener esta certificación: ¿que el Alcalde ha realizado la comprobación, simplemente?, ¿que ha sido efectuada, especificando todo aquello que se ha llevado a cabo? o también, ¿que la comprobación la hará el Secretario, de lo que certificará, una vez que así lo haya ordenado el Alcalde? Creemos que esto último será lo que acontezca. De cualquier forma, realizada esta comprobación, pueden suceder dos cosas: 
1. $\quad$ SI LA INICIATIVA CUMPLE LOS REQUISITOS, el Alcalde tiene que convocar el Pleno del Ayuntamiento cuya celebración habrá de producirse en el plazo de treinta días hábiles ${ }^{19}$, a contar desde la fecha de registro de entrada de la solicitud en el Ayuntamiento.

2. ${ }^{\circ} \quad$ SI LA INICIATIVA NO CUMPLE CON LOS REQUISITOS exigidos para ello, se abre un plazo de cinco días hábiles, a contar también desde la fecha de registro de la petición, en el que se requerirá al representante de los vecinos o vecino que firme en primer lugar, para que subsane, en el plazo de diez días hábiles, los defectos o aporte la documentación que sea procedente. Si la subsanación se produce, a partir de la fecha en la que ésta se produzca, se abrirá el plazo de treinta días para la celebración del Pleno al que se refiere el artículo 7.1.

Si no se subsana, la LRCPLA no dice qué ocurrirá. Atendiendo a lo dispuesto en el artículo 120 de la LOREG, que se remite a la Ley de Procedimiento Administrativo en todo lo no expresamente regulado en materia de procedimiento por la Ley electoral - que estimamos supletoria de la legislación andaluza-, se actuará conforme lo dispuesto en el artículo 71.1 de la Ley 30/1992, de 26 de noviembre, modificada por la Ley 4/1999, de 13 de enero (LRJAP y PAC).

Durante el plazo para requerir la subsanación y el concedido para realizarla, entendemos que queda interrumpido el plazo de los 30 días para la convocatoria y celebración del Pleno, reanudándose una vez cumplido el requerimiento. Si subsana el Alcalde podrá convocar el Pleno para decidir sobre la iniciativa del proceso de consulta.

No obstante, la LRCPLA no ha previsto qué ocurrirá en el supuesto de inactividad de la Administración municipal [ALCALDE o, en su defecto, la 1/4 de los miembros Corporación (art. 46.2.a) LRBRL] con relación al sometimiento al Pleno de la iniciativa de consulta popular solicitada por un grupo de vecinos, en el plazo regulado para ello y, por tanto, qué sentido va a tener el silencio en este caso. La LRJAP y PAC, aplicable igualmente por virtud del artículo 120 LOREG, confiere a la falta de resolución expresa efectos estimatorios. Conviene recordar que la petición de consulta popular constituye un derecho público subjetivo de los vecinos

\footnotetext{
19 Este plazo nos parece excesivo, puesto que entendemos que se puede prolongar el proceso innecesariamente. Es evidente que la LRCPLA está imponiendo que la sesión del Pleno, que ha de conocer la iniciativa de consulta, se convoque y se celebre pero lo que no obliga es que el Pleno de la Corporación se pronuncie sobre el asunto. Por tanto, debiera haberse establecido un plazo máximo para resolver sobre la petición, no para el sometimiento de la iniciativa a la Corporación.
} 
que engendra una verdadera y auténtica reclamación que ha de ser contestada, por lo que si fuere desconocido éste será exigible en vía contencioso-administrativa, como así lo tiene declarado el Tribunal Supremo en su Sentencia de 14-11-89 (Arz. 8304), al enjuiciar una denegación de consulta popular solicitada al Ayuntamiento de Sevilla.

Igualmente debe indicarse que la reforma operada en la Ley 30/1992 LRJAP y PAC exige una norma con rango de ley para que se pueda otorgar al silencio de la Administración efectos desestimatorios de la pretensión del vecino que, a nuestros efectos, es la convocatoria de una consulta popular. Ante la falta de regulación de la LRCPLA, el silencio que se produzca sobre la petición será positivo. La LRCPLA, creemos, ha dejado de tratar una cuestión cuya regulación legal es necesaria y sobre la que ya se llamó la atención cuando se tuvo oportunidad ante la Comisión del Parlamento Andaluz que conoció de esta norma y su tramitación legislativa.

\section{La información pública}

El artículo 8 de la LRCPLA establece que el acuerdo de iniciación del proceso de consulta popular tendrá dos variantes:

a) Aprobación de la iniciación del proceso de consulta popular a instancia de un grupo político municipal, por mayoría simple (arts. 8 y 6.1), y posterior sometimiento a información pública.

b) Aceptación de la solicitud de consulta popular a instancia de un grupo de vecinos, también por mayoría simple, que dará paso a la información pública (art. 8).

\section{La información pública}

Se pretende con este trámite dar a conocer suficientemente la decisión adoptada y para ello se establecen una serie de medidas:

Lugar: La Ley nos dice dónde deberá realizarse esta información, en qué medio se ha de publicar, esto es, en el BOP, concretando lo que no hacía el proyecto.

Plazo: Ha de realizarse la información pública dentro de los cincos días naturales siguientes a la aceptación o acuerdo de iniciación adoptado por el Pleno de la Corporación. El período de información pública tiene 
que ser igual o superior a veinte días hábiles, a contar desde la última publicación en el BOP y BOJA.

Acertadamente, la LRCPLA ha previsto un plazo para que el Ayuntamiento someta el acuerdo adoptado a información pública, evitándose con ello una posible causa de retraso en el desarrollo del proceso. El establecimiento de este plazo es una innovación de la Ley respecto de su proyecto.

Finalidad: Efectuar las alegaciones que tanto personas físicas como jurídicas quieran formular al respecto. Estas alegaciones también podrán ser formuladas por la Delegación del Gobierno de la Junta de Andalucía para quién la LRCPLA abre un cauce diferenciado de información, puesto que el Ayuntamiento deberá comunicarle - expresamente - el acuerdo adoptado en el plazo de 15 días hábiles (desde la adopción del acuerdo). En este sentido la Ley ha variado el texto del proyecto al añadir que «simultáneamente» habrán de realizarse ambas operaciones de información, con el consiguiente ahorro de tiempo que ello supone. No obstante, este último efecto hubiera sido mayor si el cómputo de todos los plazos de este artículo 8 hubiera sido en días naturales y no hábiles como sigue manteniendo el texto legal para las alegaciones de la Delegación del Gobierno.

\section{Acuerdo de celebración}

Concluido el período de información pública, el Pleno del Ayuntamiento debe adoptar los acuerdos que considere convenientes en orden a la celebración de la consulta, en los términos fijados en el artículo 9 LRCPLA. Para esta decisión no se fija plazo alguno, de tal forma que esa indeterminación distorsiona el proceso, dejando sin acotar ningún espacio temporal a estos efectos. Debiera existir un plazo determinado como ocurre en el artículo 7.1 para someter la iniciativa al Pleno. En cualquier caso, llegado este momento, caben dos posibles situaciones:

A) QUE SE PRESENTEN ALEGACIONES: El Pleno ponderará las que se hayan formulado y acordará lo que estime procedente. En este trámite cabe una decisión contraria a la convocatoria de la consulta, pues el Ayuntamiento en el examen de las alegaciones considerará la conveniencia y oportunidad de la petición vecinal o la iniciativa propia municipal. En cualquier caso, la decisión estará sujeta al control jurisdiccional de los Tribunales contencioso-administrativos. 
B) QUE NO HAYA ALEGACIONES: Si la iniciativa es de la propia Corporación, lo previsible en este caso es que adopte el acuerdo de celebración, mientras que si la consulta es solicitada por los vecinos cabe la posibilidad de que, en la ponderación que debe realizar el Ayuntamiento (art. 9.1), se adopte un acuerdo contrario a su celebración, siendo igualmente controlable jurisdiccionalmente.

En ambos supuestos, el acuerdo de celebración que adopte el Pleno de la Corporación precisa reunir los siguientes requisitos:

A) Para su adopción, el voto favorable de la mayoría absoluta del número legal de miembros de la Corporación (art. 71 LRBRL y art. 9.1 LRCPLA).

B) En cuanto a su contenido:

- ha de tener los términos exactos de la consulta o pregunta que se quiere formular a los vecinos;

- pueden efectuarse una o varias preguntas;

- ha de realizar la redacción inequívoca de la pregunta para que los vecinos puedan pronunciarse en sentido afirmativo o negativo.

Aunque nada dice la Ley Andaluza, también será éste el momento adecuado para que el Ayuntamiento adopte las medidas necesarias para hacer frente al coste del proceso y, por tanto, que en el acuerdo de celebración de la consulta popular se pronuncie sobre el gasto correspondiente acordando igualmente, si fuere necesario, la realización de las correspondientes modificaciones presupuestarias que se precisen para dar cumplimiento al art. 14.2 de la LRCPLA.

C) Solicitud formal al Gobierno de la Nación de la autorización de la consulta popular (lo que se deduce del art. 71 de la LRBRL) aunque nada impediría que una vez acordada, tal solicitud sea realizada por el Alcalde (art. 10.1 LRCPLA) ${ }^{20}$.

\footnotetext{
${ }^{20}$ El artículo 10.1 establece que será el municipio el que solicitará la preceptiva autorización al Gobierno, pero entendemos que ésta debe estar incluida en el acuerdo de celebración de la consulta, para que posteriormente el Alcalde efectúe la petición, en virtud de la competencia residual que éste tiene [art. 21.1.s) LRBRL].
} 


\section{Tramitación de la preceptiva autorización de la consulta}

A la regulación de este trámite se dedica el artículo 10 de la LRCPLA. La solicitud se efectuará a través de la Presidencia del Gobierno de la Junta de Andalucía (art. 10.3), a cuyos efectos se remitirá, por conducto de la Consejería de Gobernación (art. 10.2), una copia del expediente al que se unirá una certificación literal del acuerdo favorable del Pleno (arts. 204 y siguientes ${ }^{21}$ del ROF). Tampoco en este artículo 10 se fijan plazos en los que deban realizarse estas actuaciones. En el apartado 1 se recoge que el «municipio solicitará la preceptiva autorización», pero no se dice cuándo; completándose con la obligación de remisión de copia del expediente y certificación de lo acordado a la Consejería de Gobernación (art. 10.2), sin concretar en qué plazo. La actuación municipal contemplada en los artículos 9 y 10 está exenta del cumplimiento de plazo alguno que, sin embargo, sí se le fijan a la Administración andaluza en el artículo 10.3 LRCPLA.

Así, la Presidencia del Gobierno de la Junta de Andalucía emitirá informe sobre la cuestión y, en un plazo no superior a 20 días hábiles ${ }^{22}$ desde la recepción del acuerdo, lo remitirá al Gobierno de la Nación para su autorización (art. 10.3 LRCPLA).

Previa propuesta de acuerdo elaborada por la Dirección General para la Administración Local ${ }^{23}$, el Gobierno de la Nación, con base en el artículo 71 LRBRL, adoptará una de estas dos decisiones ${ }^{24}$ :

- AUTORIZAR o NO AUTORIZAR la consulta, remitiendo el acuerdo a la Presidencia de la Junta de Andalucía que, en los cinco días hábiles siguientes a la recepción del mismo ${ }^{25}$, dará traslado a la Conseje-

${ }^{21}$ Los preceptos mencionados permiten certificar al Secretario los acuerdos adoptados incluso haciendo la salvedad a la que se refiere el artículo 206 del ROF.

${ }^{22}$ El proyecto de Ley establecía un plazo de treinta días hábiles, con lo cual en este caso también el legislador andaluz ha tenido en cuenta la necesidad de reducción de plazos.

${ }^{23}$ Según se dispone por el artículo 8.1.a) del RD 1329/97, de 1 de agosto, que modifica la estructura orgánica básica del Ministerio de Administraciones Públicas.

${ }^{24}$ Véase la STS de 17-2-00 (Arz. 77) en la que se desestima el recurso contencioso-administrativo formulado por el Ayuntamiento de Algeciras (Cádiz) contra el acuerdo del Consejo de Ministros de 24-7-98, por el que se denegaba al Alcalde de dicho Ayuntamiento la autorización para la convocatoria de una consulta popular que permitiera la «articulación del municipio de Algeciras y de su entorno en la novena provincia andaluza».

${ }^{25}$ El proyecto de Ley establecía un plazo de 10 días hábiles que, como en casos anteriores, se ha tenido en cuenta la necesidad de reducción de plazos. 
ría de Gobernación para su remisión al municipio afectado ${ }^{26}$ en los dos días hábiles siguientes a la recepción del acto, decisión que es recurrible en vía jurisdiccional. El acuerdo gubernamental no autorizatorio pone fin al proceso.

Entendemos que el plazo para que el Gobierno se pronuncie, si aplicamos el artículo 120 de la LOREG, en relación con el artículo 42.3 LRJAP y PAC, será de tres meses, y en cualquier caso no podrá exceder de los seis meses (art. 42.2 LRJAP).

\section{CONVOCATORIA DE LA CONSULTA POPULAR Y DESARROLLO POSTERIOR DEL PROCESO HASTA LA VOTACIÓN}

Nos referiremos en este apartado a la convocatoria de la consulta específicamente considerada y a todas aquellas actuaciones que se llevarán a cabo desde este momento hasta el día mismo de la votación, en la que el vecino dará su opinión sobre el o los asunto/s que sean objeto de esta consulta (art. 2.1 LRCPLA).

\section{La convocatoria}

A ella se dedica el artículo 11 de la LRCPLA en su integridad. En él se han operado unas breves pero significativas modificaciones respecto del proyecto de Ley que, por un lado, agilizan el proceso y, por otro, introducen cambios que contribuirán a una reducción de gastos.

Una vez autorizada la consulta y recibida ésta en el Ayuntamiento ${ }^{27}$, se llevará a cabo la convocatoria. Se efectuará mediante decreto de la Alcaldía ${ }^{28}$, con un contenido prefijado en la Ley y que, además, debe ser hecho público mediante el $B O J A, B O P$ y otros medios que también se recogen en el artículo 11 de la LRCPLA. Esta convocatoria, y la publica-

\footnotetext{
${ }^{26}$ La Ley ha modificado el texto del proyecto, que establecía la «remisión inmediata al municipio afectado», y ha optado por fijar un plazo de remisión de dos días lo que, sin duda, evitará dilaciones innecesarias en el proceso en función a cómo se interpretara «la inmediatez» a que hacía referencia el proyecto.

${ }^{27}$ La LRCPLA (art. 10.4) alude — creemos que inadecuadamente — al municipio cuando debiera referirse al Ayuntamiento.

${ }^{28}$ En este aspecto la LRCPLA es muy respetuosa con la autonomía municipal atribuyendo esta competencia al Alcalde, lo que contrasta con la regulación que el Decreto 294/1996 de Cataluña hace al respecto, al fijar la competencia de la convocatoria al Gobierno de la Generalidad (art. 9).
} 
ción del decreto, desencadenan una serie de actuaciones posteriores cuyos plazos cuentan desde la convocatoria o desde su publicación. Unas, se llevarán a cabo ante la JEZ y, otras, por el Ayuntamiento hasta llegar al día de la votación.

El decreto de convocatoria deberá cumplir los siguientes requisitos (art. 11.1):

Plazo: Deberá ser dictado por el Alcalde dentro de los tres días hábiles siguientes a la recepción de la comunicación del otorgamiento de la autorización (art. 11.1) ${ }^{29}$.

Contenido: - Contendrá los términos exactos de la consulta, que deben coincidir con lo aprobado por el Pleno del Ayuntamiento al acordar su celebración, según el artículo 9.2 de la Ley.

— Señalará el día de la votación.

- Establecerá la duración de la campaña de información ${ }^{30}$, que se regula en el artículo 19 de la LRCPLA. Ésta no podrá tener una duración menor de diez días ni superior a quince, finalizando el día anterior a la votación, a las 0 horas.

- Indicará que corresponden a la JEZ las funciones de control y seguimiento del proceso.

Publicación: El decreto habrá de ser publicado en el BOJA, entre el día 30 y 40 anteriores a la fecha fijada para la votación (art. 11.2) ${ }^{31}$.

En los cinco días naturales ${ }^{32}$ siguientes a la publicación en $B O J A$, el decreto se insertará en el $B O P$; en el Tablón de edictos del Ayuntamiento;

${ }^{29}$ El proyecto no determinaba un plazo específico para dictar el decreto de convocatoria, con lo que la Ley al modificar este aspecto evita posibles demoras provocadas por las inactividad municipal.

${ }^{30}$ Campaña de información institucional: Desde la convocatoria y hasta el fin de la campaña de información, el Ayuntamiento podrá informar sobre fecha de la votación, procedimiento para votar, voto anticipado, pregunta objeto de consulta, todo ello sin influir en la orientación del voto, según el artículo 21 de la Ley, al que se añade respecto del proyecto un segundo apartado, que obliga al Ayuntamiento a acordar en Pleno el diseño, contenido y forma de ejecución de dicha campaña.

${ }^{31}$ Se reduce sustancialmente el plazo que a estos efectos recogía el artículo 11.2 del proyecto de ley, que lo establecía entre los cuarenta y sesenta días.

${ }^{32}$ La Ley ha añadido al texto del proyecto esta especificación que, si bien, resulta conveniente no es necesaria puesto que por aplicación de la Disposición Adicional tercera los plazos de esta Ley cuando se señalen por días, éstos serán naturales. 
y en «uno de los medios de comunicación de mayor difusión en el ámbito local correspondiente», que podrá ser cualquier medio (radio, televisión, prensa escrita, etc., municipal o no), sin que necesariamente, como decía el proyecto, tenga que ser un diario de mayor circulación en la provincia, lo que incidirá en el coste de dicha difusión.

La publicación del decreto en el BOJA es el punto de partida para la constitución de la JEZ (art. 13.1 LRCPLA), integrada con los vocales judiciales y no judiciales, a la que la Ley le encomienda, entre otras, la siguiente actuación:

- Gestionar, recibir y custodiar el voto anticipado: Se podrá votar anticipadamente ante la JEZ entre el vigésimo día siguiente a la publicación del decreto de convocatoria en el BOJA hasta el segundo día previa al fijado para la votación ${ }^{33}$ (art. 24.1 y 4 ).

Con relación al voto anticipado se precisa:

— la personación del elector ante la JEZ,

- la acreditación de su inclusión en las listas del censo electoral, mediante certificación del Secretario del Ayuntamiento,

— la identificación del elector ante el Secretario de la JEZ,

- la obtención de la documentación necesaria para emitir su voto, que será facilitada por el Secretario de la JEZ.

Una vez emitido el voto, éste quedará en poder de la JEZ hasta el día de la votación, en que será remitido a la Mesa correspondiente antes de las veinte horas.

No obstante, y ante cualquier carencia que pueda observarse en esta regulación, la LRCPLA faculta a la JEZ para que, oído el Ayuntamiento, adopte las medidas necesarias para agilizar el voto anticipado (art. 24.5).

La regulación que la LRCPLA hace de la acreditación del derecho de sufragio en el voto anticipado contrasta con la establecida para el ejercicio del voto directo en la consulta popular, al que se refiere el artículo 16. En este último la inclusión en las listas de electores se acredita «por la aportación de certificado expedido por la Delegación Provincial de la

33 El proyecto de ley no contemplaba el término del período para ejercer el voto anticipado, que la Ley ha resuelto acertadamente con la introducción del apartado 4, de este artículo 24. 
Oficina del Censo Electoral», mientras que en el artículo 24.2, se exige al elector aportar ante la JEZ «un certificado (...) expedido a este efecto por el Secretario del Ayuntamiento». ¿Por qué esta diferenciación? Si para ejercitar el voto anticipado es posible acreditar el derecho al sufragio activo con certificación del Secretario municipal, expedida con base en las Listas del censo confeccionadas por la Oficina del Censo electoral, ya no lo es para el ejercicio de este derecho ante la Mesa, en el caso de no estar incluido en las Listas que ésta maneja. Creemos que la explicación puede hallarse en el hecho de que cualquier omisión en las listas del censo sólo puede ser suplida por la certificación de la Oficina del Censo, que es la única competente para saber las circunstancias que han provocado esta omisión ${ }^{34} \mathrm{y}$, en su caso, poder rectificar o subsanar la omisión, y en definitiva, a través de esta certificación confirmar o no la existencia de este derecho de sufragio activo ${ }^{35}$. El Secretario del Ayuntamiento expide una certificación en la que, con base en los listados de la Oficina del Censo, hace fe de la inclusión de un vecino en las mismas, y si no aparece, certificará esta circunstancia, lo que permitiría al vecino subsanar el problema ante la Oficina del Censo con antelación al día de la votación.

Teniendo en cuenta la regulación del artículo 16 de la LRCPLA, no consideramos conveniente que el Secretario del Ayuntamiento expida certificaciones de inclusión en las listas electorales cuando éstas son confeccionadas y facilitadas por la Delegación de la Oficina del Censo Electoral, porque lo único que contribuye es a crear confusión. Debiera haberse seguido un mismo sistema para ambos tipos de votación. Tampoco consideramos adecuado que el Secretario sea el encargado de anotar la solicitud de esta certificación en la relación de electores que se remitirá a la mesa electoral para el día de la votación. Cualquier anotación en las listas del censo debe llevarse a cabo por la Oficina del Censo y, en lugar de hacer anotación alguna, hubiera sido más aconsejable regular que el Secretario enviara copia de la certificación a la Mesa. De esta forma se rele-

\footnotetext{
${ }^{34}$ El artículo 79 del Reglamento de Población y Demarcación territorial, en desarrollo del artículo 17.3 de la LRBRL, establece que la formación del censo de población es una competencia exclusiva del Instituto Nacional de Estadística, siendo la Oficina del Censo Electoral, encuadrada dentro de aquél, el órgano encargado de la formación del censo de electoral, ejerciendo sus competencias bajo la dirección y supervisión del la JEC (art. 29 LOREG), competencias a las que se refiere el artículo 30 de la LOREG.

${ }^{35}$ La Instrucción de 29-4-91 de la JEC, modificada por la de 28-4-93, sobre el concepto de certificación censal específica, dice que estas certificaciones no constituyen un medio extraordinario de obtener la inscripción en el censo, sino un medio de prueba de que el ciudadano de que se trate está inscrito en el censo electoral vigente, aunque no figure en los ejemplares certificados de las listas del censo puestos a disposición de las Mesas electorales. Vease el contenido de la misma en las pp. 428 a 430, del Código Electoral de Abella, ya citado.
} 
va a este funcionario de una tarea que puede ocasionarle algún que otro quebradero de cabeza ${ }^{36}$.

\section{Actuaciones del Ayuntamiento}

Gráficamente, en el cuadro anexo, se indican resumidamente todas estas actuaciones del Ayuntamiento que no ofrecen dificultad alguna, salvo la de llevarlas a cabo dentro del plazo fijado para ello, y entre ellas se encuentran las siguientes:

- Exponer en el Tablón de Anuncios, a partir del sexto día natural desde publicación de la convocatoria en BOJA, las listas electorales facilitadas por la Oficina del Censo Electoral (art. 15.2).

Estas listas estarán expuestas hasta el día de la votación y formarán parte de la documentación oficial — expediente electoral— que se remita a la Mesa (art. 15.3).

- El Ayuntamiento determinará el número, límites de las secciones electorales, sus Mesas (art. 17.1).

No se concreta qué órgano debe acordar lo procedente ni cuando debe de determinarse y al no hacerlo, por aplicación del artículo 21.1.s) LRBRL, le corresponderá la competencia al Alcalde.

- Exposición de lo determinado sobre secciones y mesas en publicación periódica local y tablón de anuncios, desde el octavo día a contar desde la convocatoria de la consulta (art. 17.2).

Esta actuación abre un período de reclamaciones de los electores, comprendido entre el octavo día desde la convocatoria al 14. ${ }^{\circ}$, es decir, dentro de los seis días desde el anuncio de la exposición en el tablón (art. 17.3), los que van desde el día $8 .^{\circ}$ al $14 .^{\circ}$ aludidos.

- Resolución de las reclamaciones por el Pleno del Ayuntamiento dentro de los cinco días siguientes al período hábil de presentación de reclamaciones, es decir, entre el $15 .^{\circ}$ y $19 .^{\circ}$ día, a contar desde la convocatoria.

${ }^{36}$ No se entenderá fácilmente que el Secretario pueda certificar en un caso (art. 24) y no en otro (art. 16). 
Las reclamaciones no debieran resolverse por el Pleno, por razones de operatividad, y por entender que debe seguir siendo una actuación de la Alcaldía, ya ésta resolvió en primer lugar, por aplicación del artículo 21.1.s) de la LRBRL. No obstante, parece que, sobre la base de quien resuelve estas reclamaciones (art. 17.3), podría ser también el Pleno el que se pronunciara en los términos del artículo 17.1 de la LRCPLA.

- Comunicación a la JEZ, dentro de los diez días naturales siguientes a la publicación de la convocatoria, los lugares gratuitos para la colocación de propaganda y locales oficiales o lugares públicos para la celebración de actos públicos (Art. 20.3).

- Formación de las mesas electorales, conforme a los artículos 26 y 27 de LOREG, realizando el sorteo para designar los presidentes y vocales de las mesas electorales entre el $10 .^{\circ}$ día y el $15 .^{\circ}$ posteriores a la publicación de la convocatoria de la consulta (art. 18.1 y 2).

- Entrega de papeletas y sobres a las mesas electorales, al menos una hora antes del comienzo de la votación (art. 22.2).

La confección de los sobres, papeletas, actas, y todo el material que formará el expediente electoral, corresponderá al Ayuntamiento, de conformidad con lo dispuesto en el artículo 14 de la Ley ${ }^{37}$.

- Decidir si realizará la campaña de información institucional, que se regula en el artículo 21.2 de la LRCPLA, y en caso afirmativo, su diseño, contenido y forma de ejecución se acordará por el Pleno. Su objeto será el determinado en el artículo 21.1 de la LRCPLA.

\section{VOTACIÓN, ESCRUTINIO GENERAL Y PROCLAMACIÓN DE RESULTADOS}

\section{Constitución de las Mesas}

El artículo 25 de la LRCPLA hace referencia al acto de constitución de las Mesas, en el que, sin lugar a dudas, debiera haberse hecho una remi-

\footnotetext{
${ }^{37}$ En el Capítulo II de la Ley hubiera sido deseable regular el modelo de urnas electorales y cabinas, salvo que esta omisión se remedie por la vía de la Disposición final segunda, que permite a la Consejería de Gobernación «dictar cuantas disposiciones sean precisas para el desarrollo y ejecución de lo previsto en la presente ley", pudiendose remitir a las normas autonómicas andaluzas, tales como los Decretos 70/1986 y 72/1986, de 23 de abril, sobre regulación de las condiciones de los locales, urnas, papeletas, sobres y demás impresos, y de las dietas y gratificaciones del personal.
} 
sión a lo dispuesto sobre la materia en el artículo 80 de LOREG, ante la falta de regulación en la Ley Electoral Andaluza.

\section{Votación y escrutinio}

El artículo 26 de la Ley reproduce, con alguna modificación, el artículo 18 de la normativa catalana, resumen de lo dispuesto en la LOREG, artículos 84 a 94, cuando regula la votación en la Sección XIII, del Capítulo VI sobre el Procedimiento Electoral.

Respecto del escrutinio por parte de la Mesa, dadas las características del proceso, se ha preferido trasladar íntegramente al texto legal andaluz lo dispuesto en la norma catalana (D. 294/1996, de 23 de julio).

Estimamos necesaria la remisión a la LOREG en todo lo no regulado por el mismo y que afecte a la votación y escrutinio en la Mesa.

\section{El escrutinio general y proclamación de resultados}

El artículo 27 de la LRCPLA mantiene el texto del proyecto con algunas variaciones de estilo de menor importancia.

Según este precepto, apartado 1, el escrutinio general se efectuará el tercer día natural siguiente al de la votación, siguiendo lo dispuesto en el artículo 103.1 de la LOREG.

En el apartado 2, alude al plazo para la presentación de reclamaciones por los grupos políticos con representación en el municipio y para los representantes de los grupos promotores de la consulta ante la JEZ y para la resolución de las mismas procediendo a la proclamación de resultados. Los acuerdos de la JEZ son recurribles ante la JEA, quién debe resolverlos en el plazo de cinco días desde la interposición del recurso, para lo que deberá seguir el procedimiento regulado en el artículo 13.3 de la LRCPLA.

Resueltas las reclamaciones, en su caso, la JEZ proclamará el resultado de la consulta remitiendo copia del acta de proclamación al Ayuntamiento ${ }^{38}$ para que proceda a su publicación en el BOJA, BOP y tablón de

\footnotetext{
38 En el proyecto, se remitía al municipio lo que ahora en la Ley ha sido oportunamente modificado para referirse al Ayuntamiento. Esta mención al municipio - cuando debe hacerse al Ayuntamiento- ha sido muy frecuente en su texto, corrigiéndose en esta Ley en dos de los casos, salvo en los artículos 10.4 y 14.2. El municipio (art. 11 LRBRL) es la entidad local básica de la organización te-
} 
anuncios de la Corporación. Simultáneamente la remitirá a la Consejería de Gobernación a los efectos de la Disposición Adicional primera sobre registro de consultas (art. 27.3). Para todo ello la LRCPLA no fija plazo alguno.

La Ley, con el fin de dar cumplimiento a las limitaciones temporales fijadas en su artículo 4, en su Disposición Adicional primera crea un Registro de Consultas reproducción del artículo 7 del Decreto catalán 294/1996, de 23 de julio.

En la Disposición Adicional segunda se contempla la cooperación de la Administración Autonómica, a través de la Consejería de Gobernación, en el desarrollo del proceso. También se prevé la asistencia «activa» de dicha Administración que habrá que ver en qué consiste tan imprecisa e indeterminada asistencia.

\section{CONCLUSIONES}

El procedimiento diseñado por la Ley 2/2001, de 3 de mayo, para la regulación de las consultas populares locales en Andalucía resulta poco dinámico. Los plazos establecidos para los distintos trámites alargan en exceso el proceso, ya que la mayoría de ellos se computan en días hábiles - lo que debiera ser la excepción - en lugar de naturales. Desde que la iniciativa se formula, no serán menos de nueves meses los que deban transcurrir hasta llegar al día de la votación, y eso contando con que todas las actuaciones se produzcan sin interrupción alguna y que la autorización del Gobierno de la Nación se obtenga en un máximo de tres meses. El legislador andaluz ha sido consciente de ello y ha tratado de reducir algunos plazos, pero el resultado final sigue siendo un proceso demasiado largo.

La Ley Andaluza 2/2001, al regular el régimen de las consultas populares, tiene presente que sus normas deben aplicarse con carácter excepcional, aunque no lo refleja expresamente. Una forma de conseguir que la petición de la consulta no deje de ser excepcional es la imputación de todos los gastos al municipio, sin que se regule la necesaria ayuda económica que, con toda seguridad, precisarán los Ayuntamientos para lograr el adecuado desarrollo de cuantas actuaciones se realicen. Este apoyo eco-

rritorial del Estado, correspondiendo su gobierno y administración al Ayuntamiento (art. $140 \mathrm{CE}$ ) integrados por el Alcaldes y Concejales (art. 19.1 y 2 del ROF), siendo el Ayuntamiento quien representa al municipio (art. 1.1 TRRL). 
nómico deberá ser prestado por la Consejería de Gobernación, una vez que el Consejo de Gobierno de la Junta de Andalucía, en virtud de las facultades que le concede la Disposición Final segunda de la Ley, dicte las disposiciones que para cada caso concreto se estimen necesarias a estos efectos. 


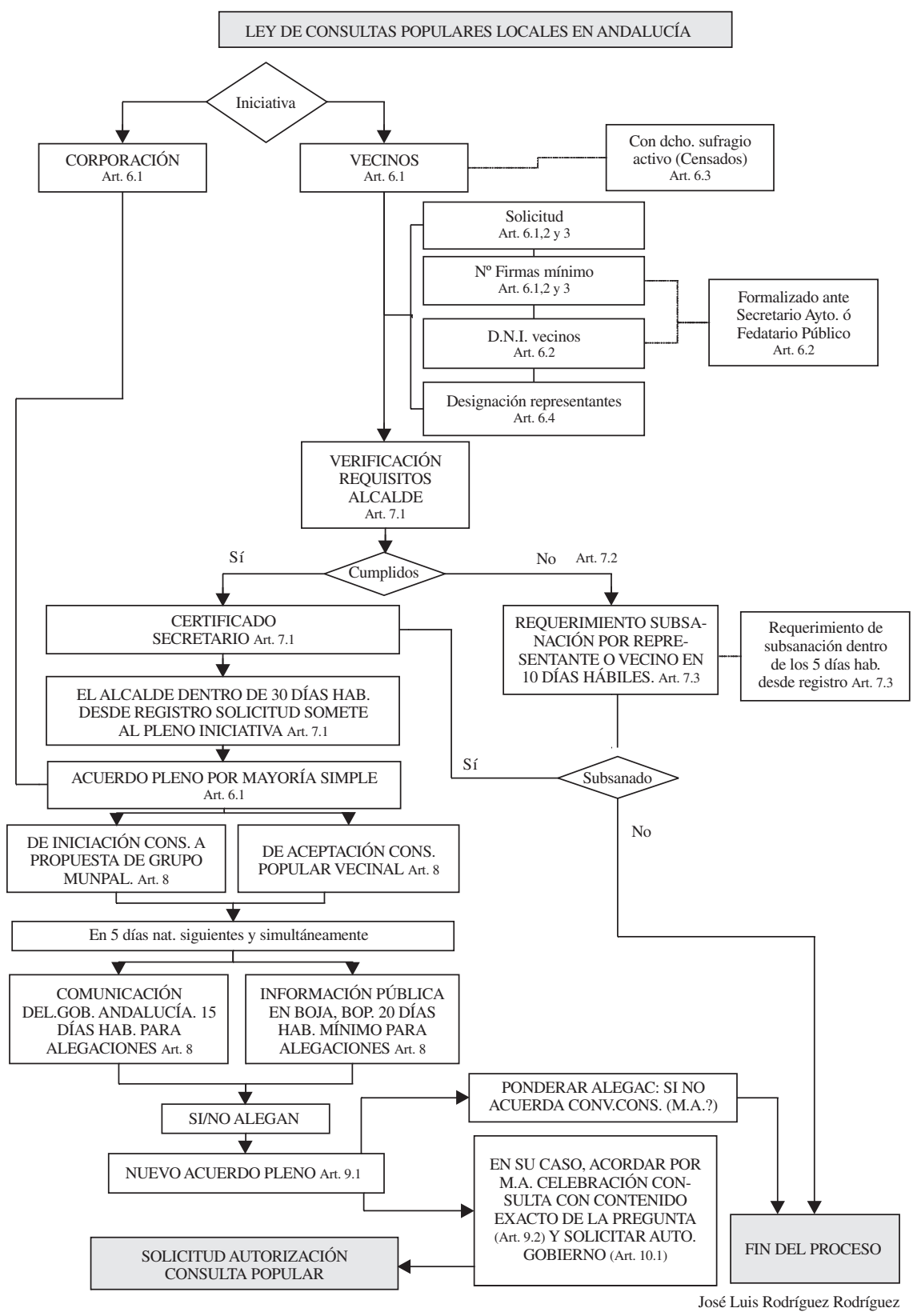




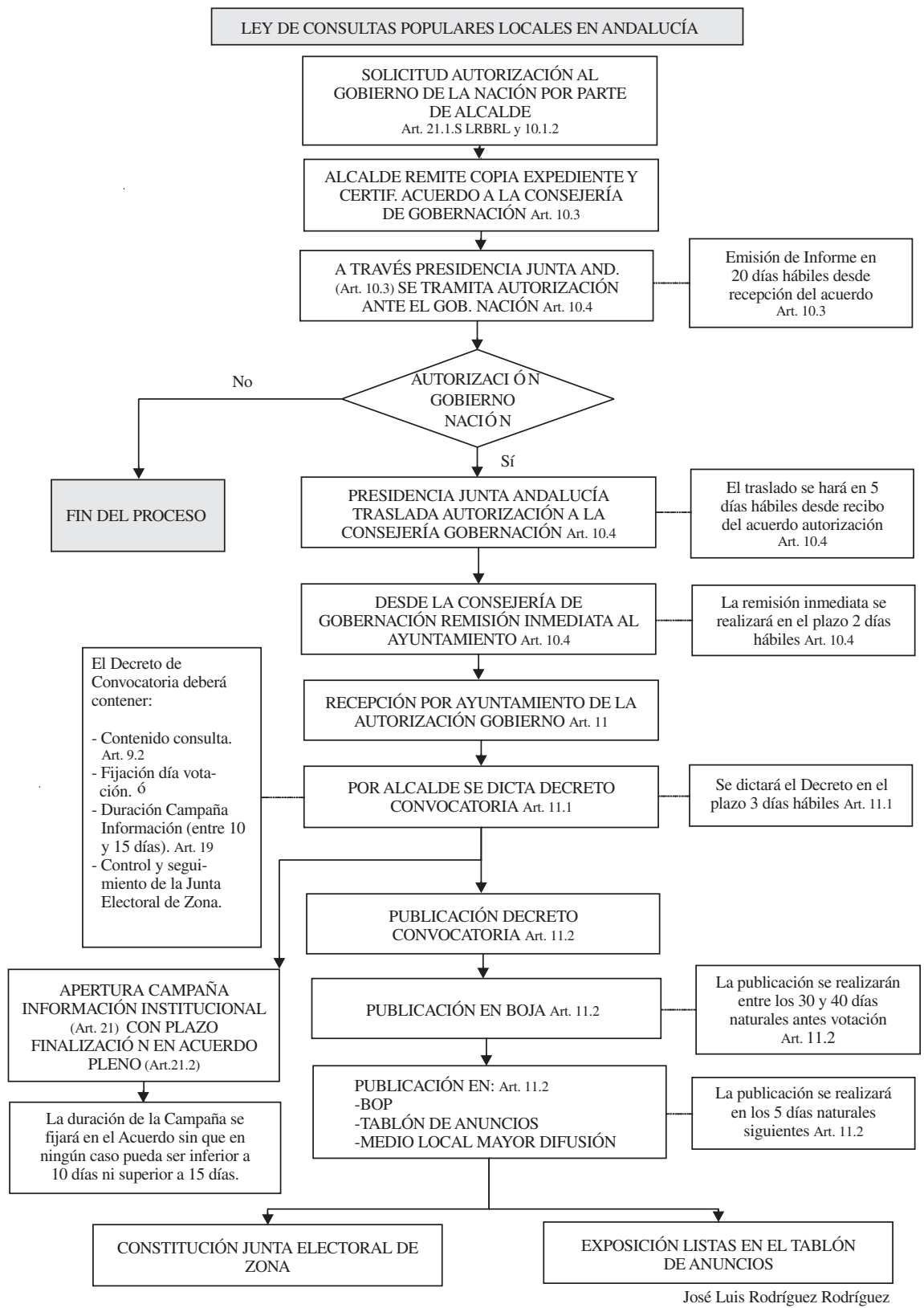




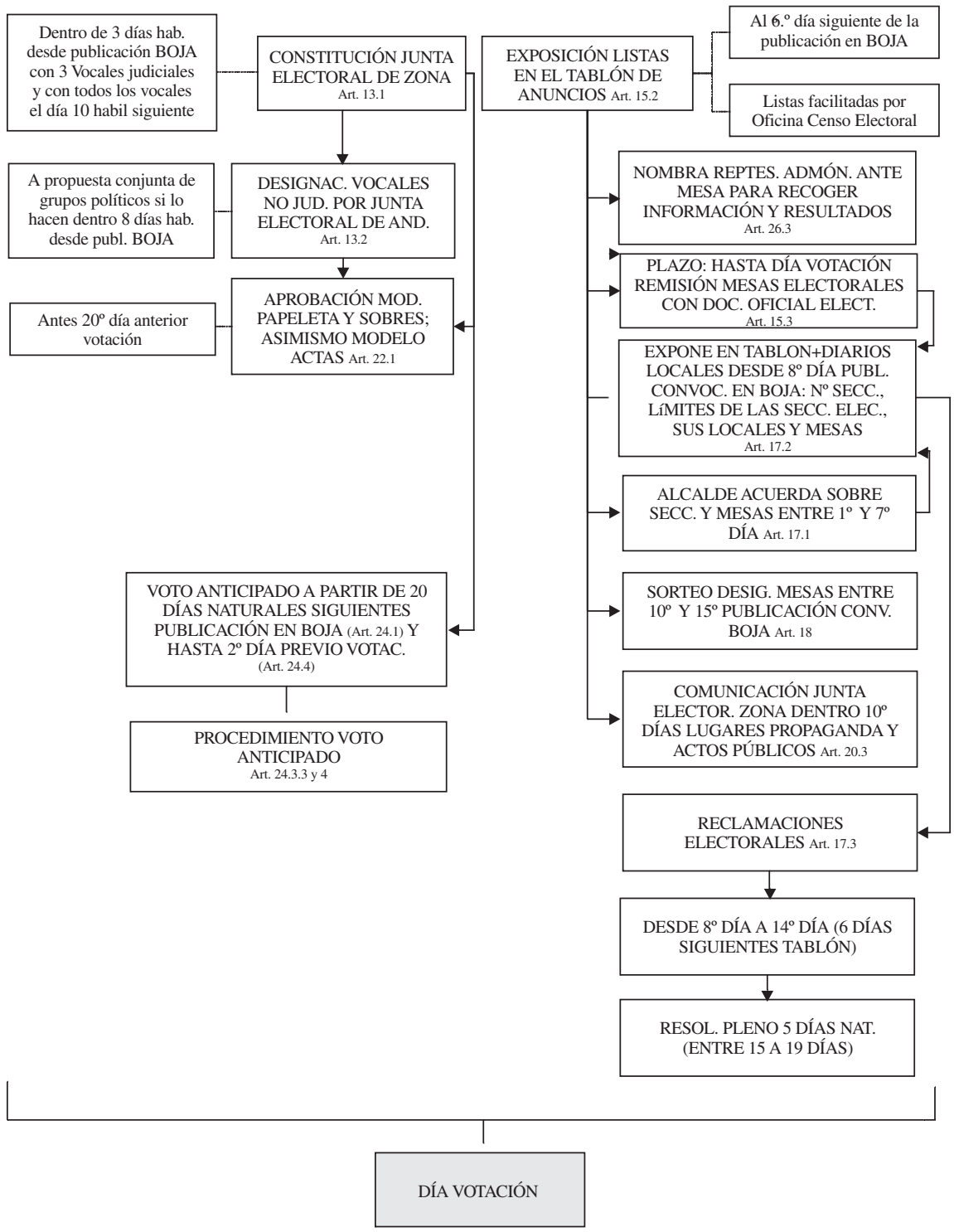




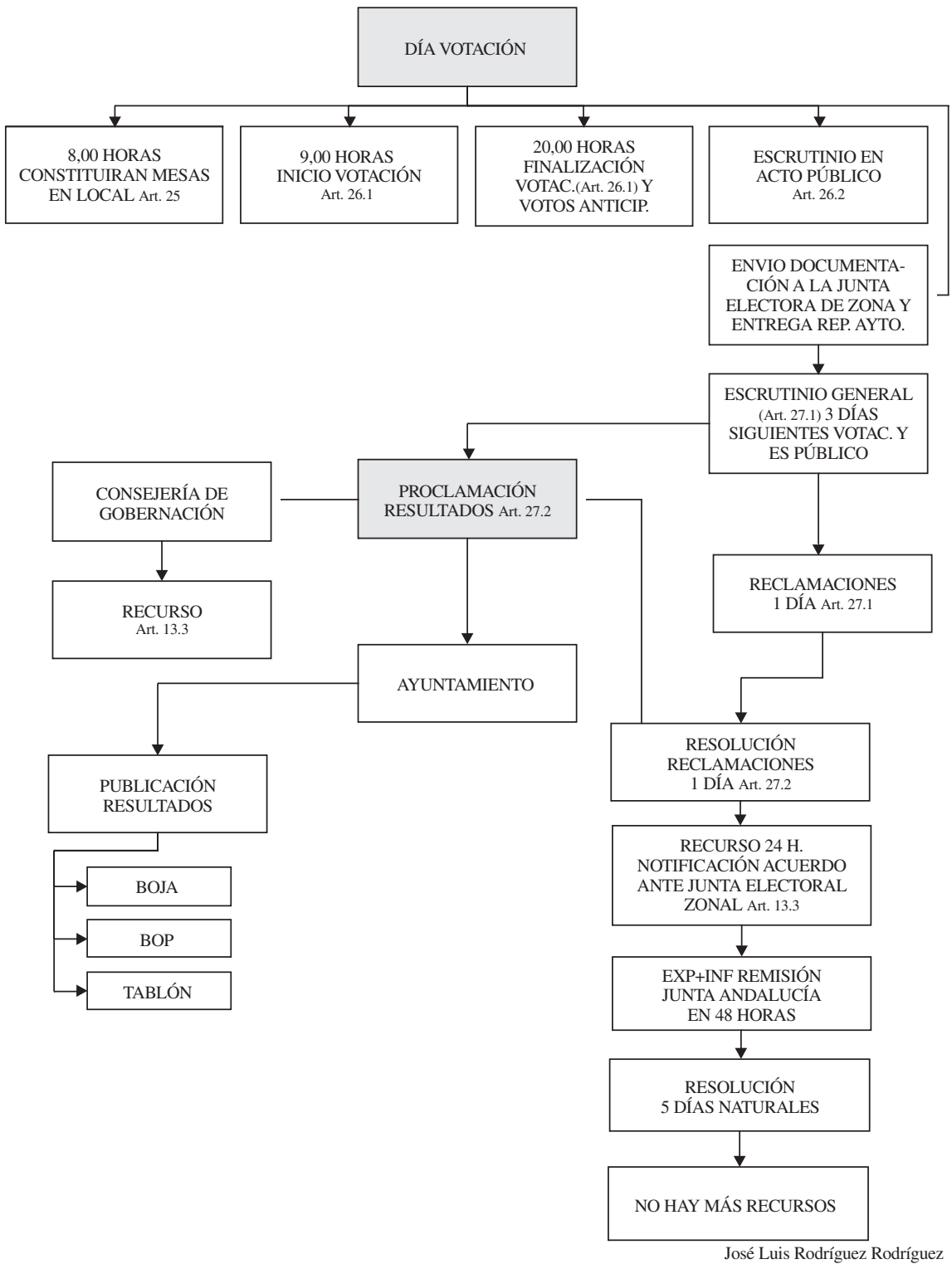




\section{Reseñas de legislación y jurisprudencia}


